\title{
What can we expect from the binding characteristics of azilsartan, a newly available angiotensin II blocker, in hypertension?
}

\author{
Kouichi Tamura, Masato Ohsawa, Tomohiko Kanaoka, Akinobu Maeda, Kengo Azushima, Kazushi Uneda, \\ Hiromichi Wakui, Koichi Azuma, Yuko Tsurumi-Ikeya and Satoshi Umemura
}

Hypertension Research (2013) 36, 107-108; doi:10.1038/hr.2012.166; published online 11 October 2012

$\mathrm{H}$ ypertension is highly prevalent worldwide and is one of the major risk factors for cardiovascular and renal diseases. In Japan, the first-line antihypertensive drugs are calcium channel blockers, angiotensin II (Ang II) type 1 receptor (AT1R) blockers (ARBs), angiotensin-converting enzyme (ACE) inhibitors, diuretics and $\beta$-blockers (including $\alpha / \beta$-blockers), according to the 2009 Japanese Society of Hypertension Guidelines for the Management of Hypertension. ${ }^{1}$ Experimental and clinical evidence has indicated that activation of the reninangiotensin system (RAS) is involved in the pathogenesis of hypertension and the related target organ damage, and multiple studies have proven the usefulness of RAS blockade induced by ACE inhibitor and ARB for the management of hypertension. In the US, a newly developed ARB, azilsartan medoxomil, a prodrug that is quickly hydrolyzed to the active moiety azilsartan, a potent, insurmountable, and highly selective ARB with estimated bioavailability of $60 \%$ and elimination half-life of $11 \mathrm{~h}$, was approved by the FDA in 2011. In 2012, the active moiety azilsartan has been approved for treatment of hypertension as the seventh clinically available ARB in Japan and also in Europe.

Although the sartan family of preceding ARBs have a common pharmacophore

K Tamura, M Ohsawa, T Kanaoka, A Maeda, K Azushima, K Uneda, H Wakui, Y Tsurumi-Ikeya and S Umemura are at the Department of Medical Science and Cardiorenal Medicine, Yokohama City University Graduate School of Medicine, Yokohama, Japan; K Azuma is at the Department of Nephrology and Hypertension, Yokohama Dai-Ichi Hospital of Zenjin Foundation, Yokohama, Japan

E-mail tamukou@med.yokohama-cu.ac.jp structure, their clinical therapeutic effectiveness is reported to differ. Although their efficacy may be related to their binding strength, this notion has changed with a better understanding of the molecular mechanism of AT1R activation. ${ }^{2-5}$ Therefore, it is plausible that each ARB differs with regard to its molecular interactions with AT1R in inducing inverse agonism. ${ }^{6}$ One of the features of azilsartan reported to date is its ability to remain tightly bound to AT1R for very long periods of time after drug washout. Previous results of time course studies of the ability of various ARBs to persistently block Ang II binding to AT1R after drug washout have shown that azilsartan dissociates from AT1R slower than other ARBs. ${ }^{7}$ In relation to the binding of ARBs to the AT1R, a series of studies by Miura's laboratory showed that small differences in the chemical structures of ligands affect the ligand-specific changes in the receptor conformation and have an influence to exert agonism, neutral antagonism or inverse agonism toward the AT1R, thereby indicating that the ligand-induced specific action on the receptor conformation with respect to the stabilization around transmembrane (TM) 3 in the AT1R is involved to induce agonist, neutral antagonist or inverse agonist activities. ${ }^{5}$

In the current issue of Hypertension Research, to elucidate the plausible molecular interactions of azilsartan with AT1R, which is relevant to the strong blood pressure (BP)lowering effect of azilsartan, Miura et al. ${ }^{8}$ analyzed the characteristics of the molecular mode of binding of azilsartan to the AT1R. Azilsartan is structurally similar to a preceding ARB cadesartan, except that it bears a 5-oxo-1,2,4-oxadiazole moiety in place of the tetrazole ring. Like candesartan, azilsartan also has a carboxyl group at the seventh position of the benzimidazole ring, which is the group that is reported to be associated with the insurmountable receptor antagonistic activity of candesartan. ${ }^{7}$ Therefore, it should be interesting whether the 5-oxo-1,2,4-oxadiazole moiety newly added to azilsartan is related to the molecular mode of binding to the AT1R and thus to the pharmacological and clinical effects of azilsartan. According to the results of molecular docking models by Miura et al. ${ }^{8}$, although both azilsartan and candesartan interact with the same sites in the AT1R $\left(\right.$ Tyr $^{113}$ in TM3, Lys ${ }^{199}$ in TM5 and Gln ${ }^{257}$ in TM6), the binding of the 5-oxo-1,2,4oxadiazole moiety of azilsartan to $\operatorname{Gl}^{257}$ of the AT1R is stronger, with appearance of the letter ' $S$ ' on the molecular model, than the binding of the tetrazole ring of candesartan to $\mathrm{Gl}^{257}$ of the receptor. They also showed that the binding of the 5-oxo-1,2,4oxadiazole moiety of azilsartan to $\mathrm{Gl}^{257}$ of the AT1R is important for azilsartan to exert the inverse agonist activity.

Then, our next interest is whether this strong binding of azilsartan to AT1R is clinically relevant in certain pathological conditions. With respect to the BP-lowering effect of azilsartan, recent studies in the US and Japan showed that azilsartan medoxomil and azilsartan have superior efficacy to other preceding ARBs, including candesartan without increasing adverse events. ${ }^{9-13}$ Presently, hypertensive patients with chronic kidney disease (CKD) and diabetes are increasing in number, and cardiovascular and renal complications are the most 
common cause of death in these patients. The BP control is an important issue in cardiovascular and renal protection in these hypertensive patients. Accumulated evidence has shown that target organ damage and prognosis are more closely associated with ambulatory BP than with office BP. Ambulatory BP monitoring can also provide information on circadian $\mathrm{BP}$ variation and short-term BP variability, which is suggested to be associated with cardiovascular and renal morbidity and mortality. ${ }^{14}$ The probable sustained BPlowering effects of azilsartan would be important, because the circadian pattern of $\mathrm{BP}$ in hypertensive patients with $\mathrm{CKD}$ and diabetes has been found to exhibit a blunted nocturnal decrease in BP, which is associated with autonomic neuropathy and nephropathy in these hypertensive patients. The loss of nocturnal BP dipping has been considered to be a risk factor for the progression of nephropathy and to be of prognostic value with respect to the target organ damage and cardiovascular morbidity in these CKD patients. ${ }^{15,16}$

With respect to the therapeutic effects of azilsartan on ambulatory BP profile, the results of a recent clinical study, which compared the BP-lowering effects of azilsartan and candesartan with ambulatory BP monitoring in Japanese grade I and II hypertensive patients, are interesting. ${ }^{13}$ After 14 weeks of treatment period, the decrease in systolic and diastolic BP were significantly greater with azilsartan than candesartan over a 24-h period, and during the daytime, nighttime and early morning, with greater trough to peak ratios for systolic and diastolic BP in the azilsartan group (systolic BP, 0.97; diastolic BP, 0.95) than in the candesartan group (systolic BP, 0.82; diastolic BP, 0.75). ${ }^{13}$ This result suggests the possibility that the superior BP-lowering effects of azilsartan over candesartan may become more apparent towards the end of the 24-h dosing interval. Further clinical studies to examine therapeutic effects of azilsartan on circadian BP variation and short-term BP variability in high-risk hypertensive patients such as those with CKD and/or diabetes, as well as beneficial pleiotropic effects on cellular mechanisms of cardiometabolic and renal disease through actions that could involve more than potent AT1R blockade of AT1R and/or strong BP lowering, are warranted ${ }^{17,18}$ (Figure 1).

\section{CONFLICT OF INTEREST}

The authors declare no conflict of interest.

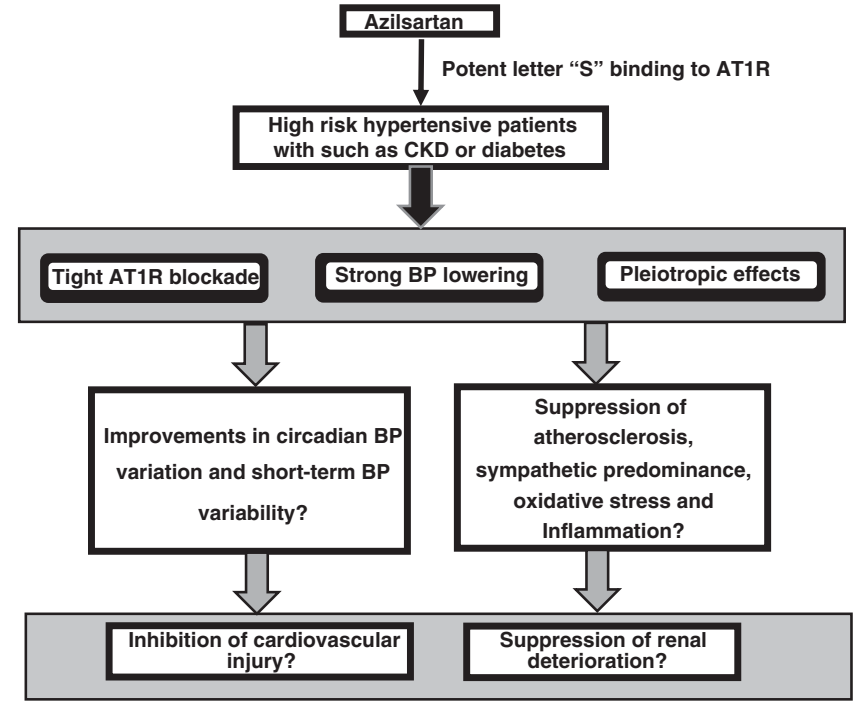

Figure 1 Is strong binding of azilsartan to AT1R is clinically relevant in high-risk hypertensive patients? Clinical studies to examine therapeutic effects of azilsartan on circadian BP variation and short-term BP variability, as well as beneficial pleiotropic effects on cellular mechanisms of cardiometabolic and renal disease in high-risk hypertension, are warranted.

1 Ogihara T, Kikuchi K, Matsuoka H, Fujita T, Higaki J, Horiuchi M, Imai Y, Imaizumi T, Ito S, Iwao H, Kario K, Kawano Y, Kim-Mitsuyama S, Kimura G, Matsubara H, Matsuura H, Naruse M, Saito I, Shimada K, Shimamoto K, Suzuki H, Takishita S, Tanahashi N, Tsuchihashi T, Uchiyama M, Ueda S, Ueshima H, Umemura S, Ishimitsu T, Rakugi $\mathrm{H}$. The Japanese Society of Hypertension Guidelines for the Management of Hypertension (JSH 2009). Hypertens Res 2009; 32: 3-107.

2 Miura S, Saku K, Karnik SS. Molecular analysis of the structure and function of the angiotensin II type 1 receptor. Hypertens Res 2003; 26: 937-943.

3 Yasuda N, Miura S, Akazawa H, Tanaka T, Qin Y, Kiya Y, Imaizumi S, Fujino M, Ito K, Zou Y, Fukuhara S, Kunimoto S, Fukuzaki K, Sato T, Ge J, Mochizuki N, Nakaya H, Saku K, Komuro I. Conformational switch of angiotensin II type 1 receptor underlying mechanical stress-induced activation. EMBO Rep 2008; 9: 179-186.

4 Qin Y, Yasuda N, Akazawa H, Ito K, Kudo Y, Liao CH, Yamamoto R, Miura S, Saku K, Komuro I. Multivalent ligand-receptor interactions elicit inverse agonist activity of $\mathrm{AT}_{1}$ receptor blockers against stretch-induced $\mathrm{AT}_{1}$ receptor activation. Hypertens Res 2009; 32 875-883.

5 Miura S, Kiya Y, Hanzawa H, Nakao N, Fujino M, Imaizumi S, Matsuo Y, Yanagisawa H, Koike H, Komuro I, Karnik SS, Saku K. Small molecules with similar structures exhibit agonist, neutral antagonist or inverse agonist activity toward angiotensin II type 1 receptor. PLoS One 2012; 7: e37974.

6 Kurtz TW, Kajiya T. Differential pharmacology and benefit/risk of azilsartan compared to other sartans. Vasc Health Risk Manag 2012; 8: 133-143.

7 Ojima M, Igata $\mathrm{H}$, Tanaka M, Sakamoto $\mathrm{H}$, Kuroita $\mathrm{T}$, Kohara $Y$, Kubo $K$, Fuse $H$, Imura $Y$, Kusumoto $K$, Nagaya $H$. In vitro antagonistic properties of a new angiotensin type 1 receptor blocker, azilsartan, in receptor binding and function studies. J Pharmaco Exp Ther 2011; 336: 801-808.

8 Miura S-i, Okabe A, Matsuo Y, Karnik SS, Saku K. Unique binding behavior of the recently approved angiotensin II receptor blocker azilsartan compared with that of candesartan. Hypertens Res 2013; 36: 134-139.

9 Bakris GL, Sica D, Weber M, White WB, Roberts A Perez A, Cao C, Kupfer S. The comparative effects of azilsartan medoxomil and olmesartan on ambulatory and clinic blood pressure. J Clin Hypertens 2011; 13: 81-88.

10 White WB, Weber MA, Sica D, Bakris GL, Perez A, Cao $C$, Kupfer S. Effects of the angiotensin receptor blocker azilsartan medoxomil versus olmesartan and valsartan on ambulatory and clinic blood pressure in patients with stages 1 and 2 hypertension. Hypertension 2011; 57: 413-420

11 Sica D, White WB, Weber MA, Bakris GL, Perez A, Cao C. Handley A, Kupfer S. Comparison of the novel angiotensin II receptor blocker azilsartan medoxomil vs. valsartan by ambulatory blood pressure monitoring J Clin Hypertens 2011; 13: 467-472.

12 Cushman WC, Bakris GL, White WB, Weber MA, Sica D, Roberts A, Lloyd E, Kupfer S. Azilsartan medoxomil plus chlorthalidone reduces blood pressure more effectively than olmesartan plus hydrochlorothiazide in stage 2 systolic hypertension. Hypertension 2012; 60: 310-318. the efficacy and safety of azilsartan with that of candesartan cilexetil in Japanese patients with grade I-II essential hypertension: a randomized, double-blind clinical study. Hypertens Res 2012; 35: 552-558.

14 Tamura K, Kanaoka T, Ohsawa M, Haku S, Azushima K, Maeda A, Dejima T, Wakui H, Ozawa M, Shigenaga A, tensive therapy based on ambulatory blood pressure profile in chronic kidney disease. Am J Cardiovasc Dis 2011; 1: 236-243.

15 Minutolo R, Agarwal R, Borrelli S, Chiodini P, Bellizzi V, Nappi F, Cianciaruso B, Zamboli P, Conte G, Gabbai FB, De Nicola L. Prognostic role of ambulatory blood pressure measurement in patients with nondialysis chronic kidney disease. Arch Intern Med 2011; 171: 1090-1098.

16 Hermida RC, Ayala DE, Mojon A, Fernandez JR. Bed time dosing of antihypertensive medications reduces cardiovascular risk in CKD. J Am Soc Nephrol 2011; 22: 2313-2321.

17 Iwai M, Chen R, Imura Y, Horiuchi M. TAK-536, a new AT1 receptor blocker, improves glucose intolerance and adipocyte differentiation. Am J Hypertens 2007; 20: 579-586.

18 Kajiya T, Ho C, Wang J, Vilardi R, Kurtz TW. Molecular and cellular effects of azilsartan: a new generation angiotensin II receptor blocker. J Hypetens 2011; 29: 2476-2483.
13 Rakugi H, Enya K, Sugiura K, Ikeda Y. Comparison of Toya Y, Umemura S. Emerging concept of anti-hyper- 